$\xi=-1$

\title{
Sparse iterative covariance-based estimation approach for processing atmospheric radar data
}

\author{
Raju $\mathbf{C}^{1}$ *, Sreenivasulu Reddy $\mathbf{T}^{1}$ \\ ${ }^{1}$ Department of ECE, Sri Venkateswara University College of Engineering, Sri Venkateswara University, \\ Tirupati, Andhra Pradesh, India \\ *Corresponding author E-mail: c.raju1112@gmail.com
}

\begin{abstract}
The Doppler estimation is an important problem for Mesosphere-Stratosphere-Troposphere (MST) Radar data for detection and estimation of the weather parameters like turbulence intensity, mean radial velocity, humidity, temperature, wind speed. For Doppler estimation, one has to compute the Power Spectral Density (PSD). Various parametric and nonparametric methods have been developed. Recently, a new category of spectrum estimation method called Sparse Iterative Covariance Based Estimation (SPICE) is also developed. SPICE is a robust, user parameter-free, high resolution, iterative and globally convergent estimation algorithm. In this paper, the simple gradient approach is used for minimization of the weighted covariance estimation analyzing the data collected from the Indian MST radar at Gadanki $\left(13.5^{\circ} \mathrm{N}, 79.2^{\circ} \mathrm{E}\right)$. The same method is applied for radar data to estimate the power spectrum and Doppler frequency. The zonal $(\mathrm{U})$, meridional $(\mathrm{V})$, wind speed $(\mathrm{W})$ are calculated and the results have been validated using simultaneous Global Positioning System (GPS) Sonde data.
\end{abstract}

Keywords: MST Radar; Doppler Profile; Power Spectral Density; SPICE; GPS Sonde.

\section{Introduction}

The Indian MST Radar located at National Atmospheric Research Laboratory, Gadanki, Andhra Pradesh, is used to study, analyze and characterize the dynamic nature of the earth's atmosphere. The atmospheric radars are used for remote sensing applications. These radars are clear air radars that can operate in VHF (30$300 \mathrm{MHz})$ and UHF $(300-3 \mathrm{GHz})$ frequency bands. The main specifications of the MST radar are given in Table 1.

The National Atmospheric Research Laboratory (NARL), Andhra Pradesh, India, has developed an algorithm to process the atmospheric data collected from MST Radar and it is called Atmospheric Data Processor (ADP) [1]. The coherent integration of the raw data (I and Q) collected by radar is performed. The presence of a quadrature component $(\mathrm{Q})$ of the signal improves the Signal to Noise Ratio (SNR). The Doppler spectrum can be improved by incoherent integration. The radar echo signal may be corrupted by clutter, system bias, interference and etc. the data is to be cleaned from these problems for analysis. After cleaning the radar spectrum the Doppler frequencies are estimated by using the maximum peak detection method. From these Doppler frequencies, radial velocities are calculated by multiplying each of the frequencies withc $/ 2 f_{c}$. Where $c$ is light velocity and $f_{c}$ is the operating frequency of the Doppler radar.
Table 1: Main Specifications of MST Radar

\begin{tabular}{|c|c|}
\hline Parameters & Specification \\
\hline Location & Gadanki $\left(13.5^{\circ} \mathrm{N}, 79.2^{\circ} \mathrm{E}\right)$ \\
\hline Frequency & $53 \mathrm{MHz}$ \\
\hline Peak Power & $2.5 \mathrm{MW}$ \\
\hline $\begin{array}{l}\text { Peak Power-Aperture } \\
\text { Product }\end{array}$ & $3 \times 10^{10} \mathrm{Wm}^{2}$ \\
\hline Maximum duty ratio & $2.5 \%$ \\
\hline Number of Yagi anten- & 1024 (East-West polarization) \\
\hline nas & 1024(North-South polarization) \\
\hline Beam width & $3^{\circ}$ \\
\hline $\begin{array}{l}\text { Number of beams for } \\
\text { automatic scan }\end{array}$ & $\begin{array}{l}18 \text { (out of } 82 \text { possible beam position in EW \& } \\
\text { NS planes) }\end{array}$ \\
\hline $\begin{array}{l}\text { Angular coverage of } \\
\text { beam scan }\end{array}$ & $\begin{array}{l} \pm 20^{\circ} \text { in both East-West and North-South planes } \\
\text { in steps of } 1^{\circ}\end{array}$ \\
\hline Pulse width & 1 to $64 \mu$ s (Uncoded/Coded) \\
\hline $\begin{array}{l}\text { Pulse Repetition Fre- } \\
\text { quency }\end{array}$ & $62.5 \mathrm{~Hz}-8 \mathrm{KHz}$ (in binary steps) \\
\hline $\begin{array}{l}\text { Maximum number of } \\
\text { coherent integrations }\end{array}$ & 512 (in binary steps) \\
\hline $\begin{array}{l}\text { Maximum number of } \\
\text { range bins, FFT Points }\end{array}$ & 512,1024 \\
\hline Radar Controller & $\begin{array}{l}\text { PC-AT Pentium-IV featuring programmable } \\
\text { experiment specification file. } \\
\text { PC-AT Pentium-IV system with ADSP } 21060\end{array}$ \\
\hline Computer system & $\begin{array}{l}\text { DSP processors for data acquisition and pro- } \\
\text { cessing. }\end{array}$ \\
\hline
\end{tabular}

As per the literature, the different algorithms have been developed to estimate the Doppler frequencies for the MST radar data. Adaptive estimates technique for the estimating the spectral moments of radar data has been applied in [2]. Multitaper spectral estimation [3] and Bispectral-based estimation [4] have been used for analysis of the MST radar data. Principle component analysis (PCA) has been presented in [5]. The algorithms have failed to give accu- 
rate results. Hence, there is a need to implement better algorithm for precise estimation of wind parameters at higher altitudes.

Recently, SPICE (Semiparametric/Sparse Iterative Covariancebased Estimation), a new technique for spectral estimation, motivated by the ideas from sparse estimation, has been introduced [6]. SPICE, a user parameter-free iterative method which offers superior resolution, have low side lobe levels and is guaranteed to converge globally. The flowchart of the proposed algorithm is shown in Fig.1.In this paper, the minimization criterion is solved using the gradient approach that is cyclic which converges globally and monotonically decreases.

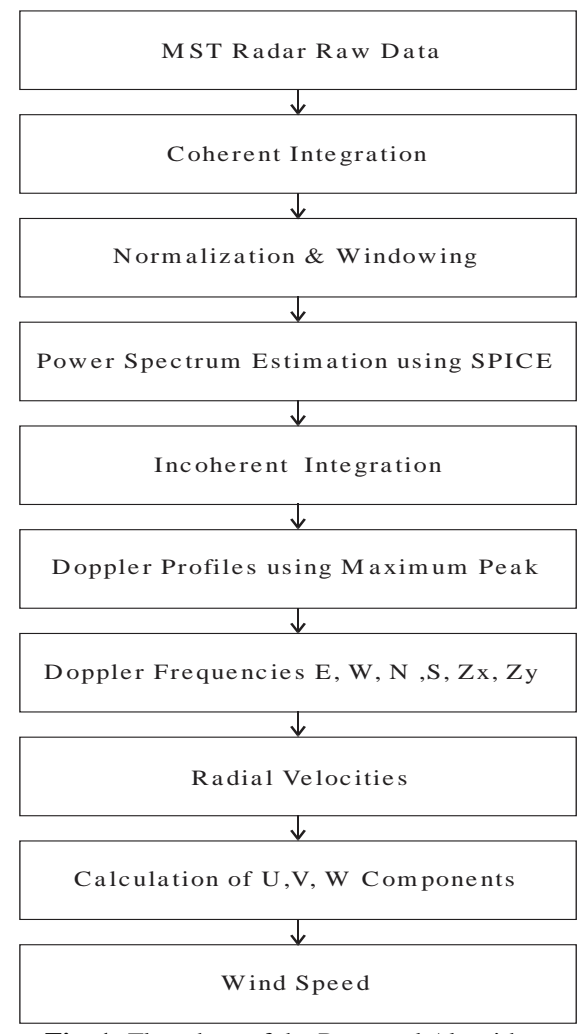

Fig. 1: Flowchart of the Proposed Algorithm.

The paper is organized as follows. The data model is given in section 2. In section 3, the gradient approach based SPICE algorithm is discussed. The results of MST Radar are given in section 4. The conclusion of the paper is discussed in section 5 .

In this paper, lowercase boldface letters represent vectors whereas uppercase boldcase letters represent matrices. Normal letters are used to indicate scalar quantities. Notations $|\cdot|,\|\cdot\|,(\cdot)^{*},(\cdot)^{\mathrm{T}}$, and $\mathrm{E}(\cdot)$ denote the modulus, the Frobenius norm, the complex conjugate transpose (Hermitian transpose), the transpose and the expectation operator respectively. Subscript $[.]_{\mathrm{k}}$ denotes the $\mathrm{k}^{\text {th }}$ element of a vector, and $\mathbf{I}_{\mathbf{N}}$ represents an identity matrix of size $\mathrm{N}$.

\section{Problem formulation}

Let $y\left(t_{n}\right)$ be the complex data obtained by weighted combination of $C$ complex exponentials with frequencies $\left\{\Omega_{\mathrm{r}}\right\}_{\mathrm{r}=1}^{\mathrm{N}} \in\left[0, \Omega_{\max }\right]$ with zero mean.

$y\left(t_{n}\right)=\sum_{r=1}^{C} q_{r} e^{j \omega_{r} t_{n}}+e\left(t_{n}\right) ;$

where $C$ is a small number, $\left\{t_{n}\right\}_{n=1}^{N}$ denotes the sampling time instants which can be non-uniformly spaced. $\mathrm{q}_{\mathrm{r}}$ is the magnitude associated with $\mathrm{r}^{\text {th }}$ frequency component $\Omega_{\mathrm{r}}, \mathrm{e}\left(\mathrm{t}_{\mathrm{n}}\right)$ is the additive white Gaussian noise component corresponding to the $n^{\text {th }}$ sampling time.

Consequently the complex data signal can be modeled as

$y\left(t_{n}\right)=\sum_{r=1}^{R} q_{r} e^{j \omega_{r} t_{n}}+e\left(t_{n}\right)$
The expanded version of the above equation is

$\left[\begin{array}{c}y\left(t_{1}\right) \\ \vdots \\ y\left(t_{N}\right)\end{array}\right]=\left[\begin{array}{ccc}e^{j \omega_{1} t_{1}} & \cdots & e^{j \omega_{R} t_{1}} \\ \vdots & \cdots & \vdots \\ e^{j \omega_{1} t_{N}} & \cdots & e^{j \omega_{R} t_{N}}\end{array}\right]\left[\begin{array}{c}q_{1} \\ \vdots \\ q_{R}\end{array}\right]+\left[\begin{array}{c}e\left(t_{1}\right) \\ \vdots \\ e\left(t_{N}\right)\end{array}\right]$

Those values of $\mathrm{r}$ for which $\omega_{\mathrm{r}} \in\left\{\Omega_{\mathrm{r}}\right\}_{\mathrm{r}=1}^{\mathrm{N}}$, the corresponding $\mathrm{q}_{\mathrm{r}}$ values will be non-zero. Since $\mathrm{C}$ is small, the number of non-zero $\mathrm{q}_{\mathrm{r}}$ values will also be small. This indicates the presence of only the few corresponding frequency components, making the spectrum sparse in nature.

The equation can vectorially be represented in the following form:

$\mathbf{y}=\sum_{\mathrm{r}=1}^{\mathrm{R}} \mathbf{d}\left(\omega_{\mathrm{r}}\right) \mathrm{q}_{\mathrm{r}}+\mathbf{e}$

Where $\mathrm{d}\left(\omega_{\mathrm{r}}\right)$ is defined in the form of $\mathrm{N}$ sinusoidal components with frequencies $\omega_{\mathrm{r}}$ as

$\mathbf{d}\left(\omega_{\mathrm{r}}\right)=\left[\begin{array}{c}\mathrm{e}^{\mathrm{j} \omega_{1} \mathrm{t}_{1}} \\ \vdots \\ \mathrm{e}^{\mathrm{j} \omega_{\mathrm{r}} \mathrm{t}_{\mathrm{N}}}\end{array}\right]=\mathbf{d}_{\mathrm{r}}$

Here $\mathbf{y}=\left[y\left(t_{1}\right), y\left(t_{2}\right), \ldots, y\left(t_{N}\right)\right]^{T} \cdot\left|q_{r}\right|^{2}$ is the power value associated with the $\mathrm{r}^{\text {th }}$ frequency component that has to be estimated.

The MST radar data collected from the NARL is a uniformly sampled complex baseband signal consisting of in-phase I and quadrature-phase Q components. Similar to the case of the test signal, the spectrum of the MST radar data is seen to have one or at the most two Doppler frequencies, which again explains the reason behind the application of sparse spectrum estimation algorithm.

\section{SPICE algorithm}

The covariance matrix of the received signal is given by the following model

$\mathbf{R}=\mathrm{E}\left(\mathbf{y y}^{*}\right)=\sum_{\mathrm{r}=1}^{\mathrm{R}}\left|\mathrm{q}_{\mathrm{r}}\right|^{2} \mathbf{d}_{\mathrm{r}} \mathbf{d}_{\mathrm{r}}^{*}+\mathrm{E}\left(\mathbf{e e}^{*}\right)=\mathbf{D P} \mathbf{D}^{*}$

where

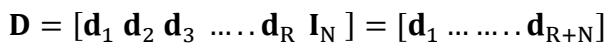

$E\left(\mathbf{e e}^{*}\right)=\left[\begin{array}{cccc}\sigma_{1} & 0 & \cdots & 0 \\ 0 & \sigma_{2} & \cdots & \vdots \\ \vdots & \vdots & \ddots & \vdots \\ 0 & \cdots & \cdots & \sigma_{N}\end{array}\right]$

$\boldsymbol{P}=\left[\begin{array}{ccccccc}\left|q_{1}\right|^{2} & 0 & \cdots & \cdots & \cdots & \cdots & 0 \\ 0 & \left|q_{2}\right|^{2} & 0 & \cdots & \cdots & \cdots & \vdots \\ \vdots & \vdots & \ddots & \ddots & \vdots & \vdots & \vdots \\ \vdots & \vdots & \vdots & \left|q_{R}\right|^{2} & \ddots & \vdots & \vdots \\ \vdots & \vdots & \vdots & \vdots & \sigma_{1} & \vdots & \vdots \\ \vdots & \vdots & \vdots & \vdots & \vdots & \ddots & \vdots \\ 0 & \cdots & \cdots & \cdots & \cdots & \cdots & \sigma_{N}\end{array}\right]$

$=\left[\begin{array}{ccccccc}m_{1} & 0 & \ldots & \ldots & \ldots & \ldots & 0 \\ 0 & m_{2} & 0 & \ldots & \ldots & \ldots & \vdots \\ \vdots & \vdots & \ddots & \ddots & \vdots & \vdots & \vdots \\ \vdots & \vdots & \vdots & m_{R} & \ddots & \vdots & \vdots \\ \vdots & \vdots & \vdots & \vdots & m_{R+1} & \vdots & \vdots \\ \vdots & \vdots & \vdots & \vdots & \vdots & \ddots & \vdots \\ 0 & \ldots & \ldots & \ldots & \ldots & \cdots & m_{R+N}\end{array}\right]$ 
where $\left\{m_{i}\right\}_{i=1}^{R+N}$ is the replacement for $\left\{\left|q_{i}\right|^{2}\right\}_{i=1}^{R+N}$. The noise components are uncorrelated to each other and are true in many practical applications. The first $\mathrm{R}$ diagonal elements of the matrix $\mathbf{P}$ denote the power values that are to be estimated and the remaining $\mathrm{N}$ diagonal elements denote the noise variance values $(\sigma)$. While equation (6) gives the true covariance matrix $\mathbf{R}$ that are dependent on the true power values, the covariance matrix computed from the data samples y can be denoted as $\widehat{\mathbf{R}}$. The SPICE algorithm deals with a weighted covariance criterion that minimizes the following

$f=\left\|\mathbf{R}^{-1 / 2}\left(\mathbf{y y}^{*}-\mathbf{R}\right)\right\|_{F}^{2}$

where $\mathbf{R}^{-1 / 2}$ denotes the Hermitian square root of $\mathbf{R}^{-1},\|\cdot\|_{F}$ denotes the Frobenius norm for matrices. For a matrix $\mathbf{X}$, the Frobenius norm can be defined as trace $\left(\mathbf{X}^{*} \mathbf{X}\right)$.

A simple calculation shows that

$$
\mathrm{f}=\operatorname{tr}\left[\left(\mathbf{y} \mathbf{y}^{*}-\mathbf{R}\right) \mathbf{R}^{-1}\left(\mathbf{y} \mathbf{y}^{*}-\mathbf{R}\right)\right]
$$

Further simplification leads to

$\mathrm{f}=\|\mathbf{y}\|_{2}^{2} \mathbf{y}^{*} \mathbf{R}^{-1} \mathbf{y}+\operatorname{tr}\{\mathbf{R}\}+$ constant.

or equivalently,

$\mathbf{y}^{*} \mathbf{R}^{-1} \mathbf{y}+\frac{1}{\|\mathbf{y}\|_{2}^{2}} \sum_{\mathrm{r}=1}^{\mathrm{R}+\mathrm{N}} \mathrm{w}_{\mathrm{r}} \mathrm{m}_{\mathrm{r}}, \mathrm{w}_{\mathrm{r}}=\left\|\mathbf{d}_{\mathrm{r}}\right\|_{2}^{2}$

We can rewrite the SPICE criterion as

$\min _{\left\{\mathrm{m}_{\mathrm{r}}\right\}} \mathbf{y}^{*} \mathbf{R}^{-1} \mathbf{y}+\sum_{\mathrm{r}=1}^{\mathrm{R}+\mathrm{N}} \mathrm{w}_{\mathrm{r}} \mathrm{m}_{\mathrm{r}}$

when $\left\|\mathbf{d}_{\mathrm{r}}\right\|_{2} \equiv$ const., 1 's can be used to replace the weights in (13).

The cyclic minimization can be preferred to SOCP which can converge globally and decreases monotonically at every iteration.

$\mathrm{m}_{\mathrm{r}}(\mathrm{i}+1)=\frac{\mathrm{m}_{\mathrm{r}}(\mathrm{i})\left|\mathbf{d}_{\mathrm{r}}^{*} \mathbf{R}^{-1}(\mathrm{i}) \mathbf{y}\right|}{\mathrm{w}_{\mathrm{r}}^{\frac{1}{2}}}$

where $r=1,2, \ldots, R+N$ and $\mathbf{R}^{-1}(\mathrm{i})=\operatorname{Ddiag}(\mathbf{P}) \mathbf{D}^{*}$ denotes the covariance matrix estimate at each iteration $\mathrm{i}$.

Here we use a simple gradient approach [7], [8], [9] for solving

(13) i.e., instead of using cyclic minimization technique.

The derivative of (13) with respect to $m_{r}$ is equal to

$-\mathbf{y}^{*} \mathbf{R}^{-1} \frac{\partial \mathbf{R}}{\partial \mathrm{m}_{\mathrm{r}}} \mathbf{R}^{-1} \mathbf{y}+\mathrm{w}_{\mathrm{r}}=-\left|\mathbf{d}_{\mathrm{r}}^{*} \mathbf{R}^{-1} \mathbf{y}\right|^{2}+\mathrm{w}_{\mathrm{r}}$

Consequently, the $(i+1)$ th iteration of a gradient algorithm applied to (13) with variable step size is given by

$\mathrm{m}_{\mathrm{r}}(\mathrm{i}+1)=\mathrm{m}_{\mathrm{r}}(\mathrm{i})-\rho_{\mathrm{r}}(\mathrm{i})\left(\mathrm{w}_{\mathrm{r}}-\left|\mathbf{d}_{\mathrm{r}}^{*} \mathbf{R}^{-1}(\mathrm{i}) \mathbf{y}\right|^{2}\right)$

The step size $\rho_{r}(i)$ must be non-negative

$\rho_{r}(i) \geq 0$.

By definition $\left\{m_{r}(i+1) \geq 0\right\}$, we can choose $\rho_{r}(i)$ such that:

$m_{r}(i) \geq 0 \Rightarrow m_{r}(i+1) \geq 0$

Let us select

$\rho_{r}(i)=\frac{m_{r}(i)}{w_{r}+w_{r}^{1 / 2}\left|\boldsymbol{d}_{r}^{*} \boldsymbol{R}^{-1}(i) \boldsymbol{y}\right|}$

which satisfies (17). A simple calculation yields $m_{r}(i+1)=\frac{m_{r}(i) w_{r}+m_{r}(i) w_{r}^{1 / 2}\left|\boldsymbol{d}_{r}^{*} \boldsymbol{R}^{-1}(i) \boldsymbol{y}\right|-m_{r}(i) w_{r}+m_{r}(i)\left|\boldsymbol{d}_{r}^{*} \boldsymbol{R}^{-1}(i) \boldsymbol{y}\right|^{2}}{w_{r}+w_{r}^{1 / 2}\left|\boldsymbol{d}_{r}^{*} \boldsymbol{R}^{-1}(i) \boldsymbol{y}\right|}$

$m_{r}(i+1)=\frac{m_{r}(i)\left|\boldsymbol{d}_{r}^{*} \boldsymbol{R}^{-1}(i) \boldsymbol{y}\right|}{w_{r}^{1 / 2}}$

and thus (18) is satisfied. when $w_{r}=\left\|\boldsymbol{d}_{r}\right\|_{2}^{2},(20)$ is the SPICE algorithm in equation (14).

The step size $\rho_{r}(i)$ in (16) can be selected in many different ways than that of (19) due to the gradient approach, to get alternative algorithms to (20).

The simple choice that can satisfy (17) is

$\rho_{r}(i)=\frac{m_{r}(i)}{w_{r}}$

and leads to

$m_{r}(i+1)=\frac{m_{r}(i)\left|\boldsymbol{d}_{r}^{*} \boldsymbol{R}^{-1}(i) \boldsymbol{y}\right|}{w_{r}}$

when $w_{r}=\left\|\boldsymbol{d}_{r}\right\|_{2}^{2}$, (22) minimizes the same as (20) and hence referred to as SPICE $_{\mathrm{b}}$.

They have different rates of convergence though they share the similar stationary points. The step size in (19) is smaller than (21), when both are evaluated using the same $\left\{m_{r}(i)\right\}$.

The both algorithms can be initialized with the power estimates obtained by means of the periodogram method.

$m_{r}(0)=\frac{\boldsymbol{d}_{r}^{*} \widehat{\boldsymbol{R}} \boldsymbol{d}_{r}}{\left\|\boldsymbol{d}_{r}\right\|_{2}^{4}}, r=1,2, \ldots, R+N$

The convergence condition for the termination of both the algorithms is

$\|\boldsymbol{m}(i+1)-\boldsymbol{m}(i)\|_{2} /\|\boldsymbol{m}(i)\|_{2}<10^{-3}$

Algorithm:

1) Read the MST Radar time-series data.

2) Initialize the initial value $m_{r}(0)$ using the periodogram equation (23)

3) Compute the covariance matrix $\mathbf{R}=\sum_{\mathrm{r}=1}^{\mathrm{R}+\mathrm{N}} \mathrm{m}_{\mathrm{r}} \mathbf{d}_{\mathrm{r}} \mathbf{d}_{\mathrm{r}}^{*}$.

4) Update $\widehat{m}_{r}(i+1)$ using the equation (21) for $\mathrm{r}=1,2, \ldots ., \mathrm{R}+\mathrm{N}$.

5) Repeat steps 2 to 4 until the convergence condition (24) is reached.

6) Calculate the Doppler profiles, Zonal, Meridional and Wind Speeds.

\section{Results}

The radar data is collected from the Indian MST radar, which is operated at the NARL, Gadanki, Andhra Pradesh. The MST radar data collected from NARL is one of the formats of 15 scans, with each scan containing signal information from six beam directions (i.e., East, West, Zenith-X, Zenith-Y, North and South). Each of the beams contains 147 height range bins with a resolution of $150 \mathrm{~m}$, starting from $3.6 \mathrm{~km}$ and extending up to a height of 25.6 $\mathrm{km}$. Each range bin contains complex time-series data with 512 samples. The power spectrum of the collected data is determined using the proposed algorithm. The complex time-series data with 512 samples is subjected to the ADP, which basically employs the method of periodogram for estimating the power spectrum. The Doppler profile is derived using maximum peak method after finding out the Doppler frequencies for all the range bins.

Once the Doppler frequencies are computed, the Doppler velocities are found out by multiplying each of the frequencies with $c / 2 f_{c}$ where $c$ is the velocity of light and $f_{c}$ is the operating frequency of the Doppler radar. Both Doppler frequencies and the velocities are calculated for all 6 beams and 147 range bins. Using the Doppler velocities for the 6 beams with subscripts representing 
the corresponding beams namely $\mathrm{v}_{\mathrm{E}}, \mathrm{v}_{\mathrm{W}}, \mathrm{v}_{\mathrm{ZX}}, \mathrm{v}_{\mathrm{ZY}}, \mathrm{v}_{\mathrm{N}}, \mathrm{v}_{\mathrm{S}}$, the three wind velocities are evaluated as follows

$\left[\begin{array}{c}\mathrm{v}_{\mathrm{x}} \\ \mathrm{v}_{\mathrm{y}} \\ \mathrm{v}_{\mathrm{z}}\end{array}\right]=\left[\begin{array}{ccc}0.603 & 0 & 0 \\ 0 & 0.603 & 0 \\ 0 & 0 & 0.603\end{array}\right]^{-1} *\left[\begin{array}{c}0.1736\left(\mathrm{v}_{\mathrm{E}}-\mathrm{v}_{\mathrm{W}}\right) \\ 0.1736\left(\mathrm{v}_{\mathrm{N}}-\mathrm{v}_{\mathrm{S}}\right) \\ 0.1736\left(\mathrm{v}_{\mathrm{ZX}}-\mathrm{v}_{\mathrm{ZY}}\right)\end{array}\right]$

Where $\mathrm{v}_{\mathrm{x}}, \mathrm{v}_{\mathrm{y}}, \mathrm{v}_{\mathrm{z}}$ are the zonal $\mathrm{U}$, meridional $\mathrm{V}$, and the vertical $\mathrm{Z}$ velocity components. The Zenith-X and Zenith-Y beams are in the vertical direction and do not play a role in the determination of the wind velocity.

The Wind speed $\mathrm{W}$ is computed as

$\mathrm{W}=\left(\mathrm{v}_{\mathrm{x}}^{2}+\mathrm{v}_{\mathrm{y}}^{2}\right)^{1 / 2}$

The wind speed thus obtained is then compared with the corresponding wind speed collected from the Global Positioning System (GPS) radiosonde.

Fig. 2 shows the output SNR estimated from power spectrum obtained using periodogram and SPICE method for the east beam for the MST radar data collected on February 9, 2015.As more noise is seen in higher range bins, the figure has been depicted from 11 to $22 \mathrm{Km}$ only. From Fig. 2, it is apparent that the SPICE gives more SNR values than the existing method for East beam. The output SNR is obtained using the method proposed in Hilderband and Sekhon [10].

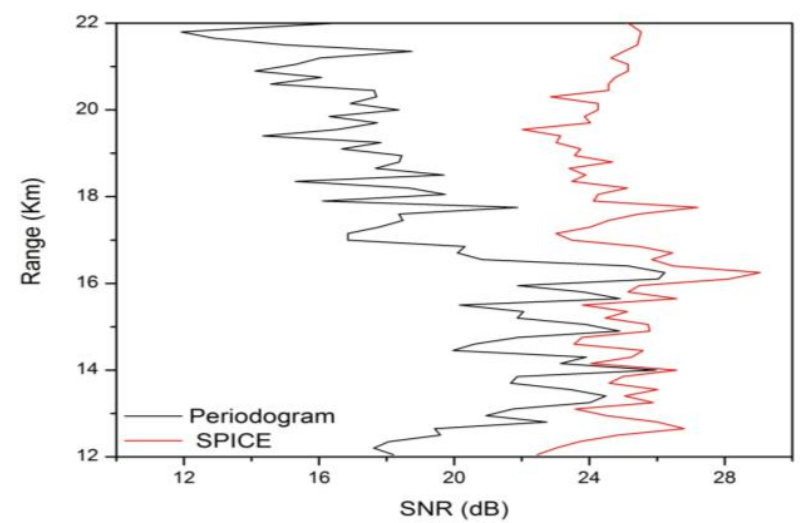

Fig. 2: Height Profiles of SNR Estimated Using Periodogram and SPICE for East Beam.

The comparison of average SNR values in $\mathrm{dB}$ for six beams on February 9 and 10, 2015 for the two algorithms is given in Table 2. From Table 2, it is seen that SPICE gives the better improvement in average SNR values over the existing algorithm periodogram.

Table 2: Comparison of Average SNR for Two Algorithms

\begin{tabular}{llllll}
\hline Date & Algorithm & East & West & North & South \\
\hline \multirow{2}{*}{ Feb 9, 2015 } & Periodogram & 19.47 & 18.23 & 20.14 & 21.57 \\
& SPICE & 24.45 & 23.87 & 22.98 & 24.48 \\
\multirow{2}{*}{ Feb 10, 2015 } & Periodogram & 22.35 & 23.41 & 18.56 & 17.86 \\
& SPICE & 25.76 & 24.38 & 20.86 & 19.47 \\
\hline
\end{tabular}

The distinctive spectra of the collected data on February 9, 2015, for east beam before and after denoising are shown in Fig. 3.
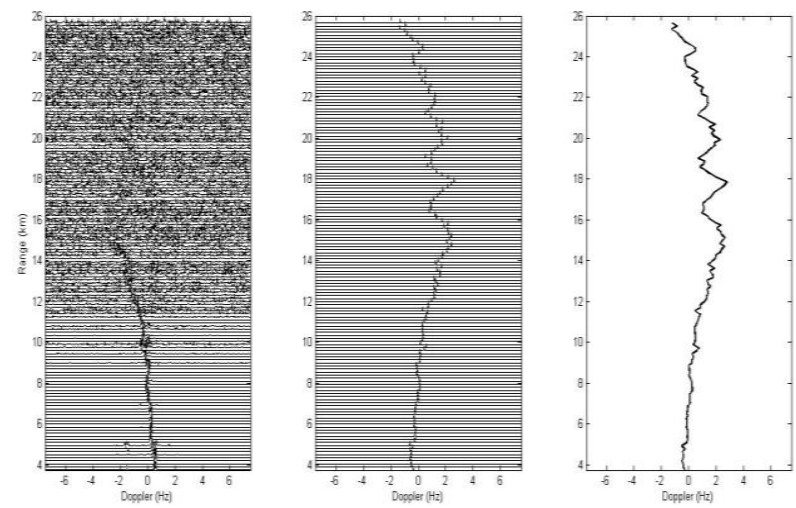

Fig. 3: Distinctive Spectra of East Beam (February 9, 2015) (A) before Denoising (B) after Denoising (C) Doppler Profile.

The Zonal $\mathrm{v}_{\mathrm{x}}$, meridional $\mathrm{v}_{\mathrm{y}}$ components calculated using the SPICE, periodogram and GPS radiosonde are shown in Fig. 4 (a) and (b) respectively. The windspeed W is calculated using (24) is shown in Fig. 5. From the figure, it is shown that the proposed algorithm is following the GPS radiosonde data for both the dates Feb 9, 2015 and Feb 10, 2015.

To test the stability of the algorithm, the correlation between GPS radiosonde data and the proposed algorithm wind speed is displayed in Fig 8 for radar data collected during $9^{\text {th }}$ to $12^{\text {th }}$ February, 2015. We get a correlation coefficient of 0.96645 between the GPS and SPICE.

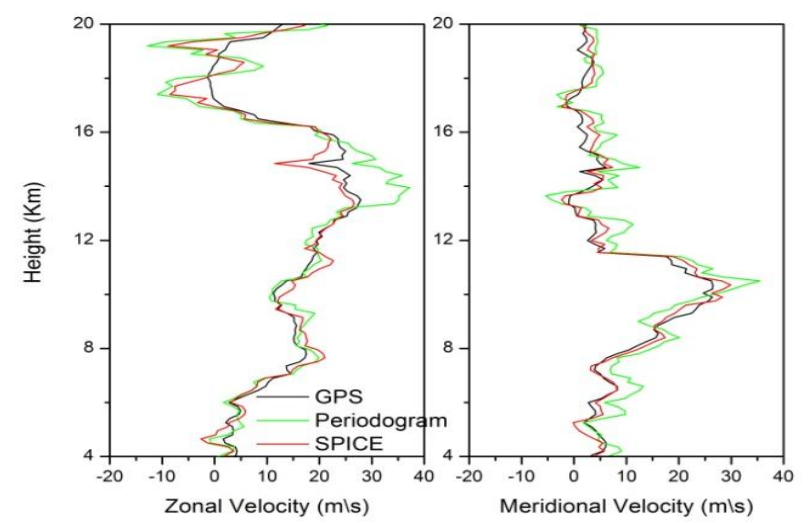

Fig. 4: Zonal and Meridional Velocities for February 9, 2015 Data Using.

GPS radiosonde, SPICE and periodogram

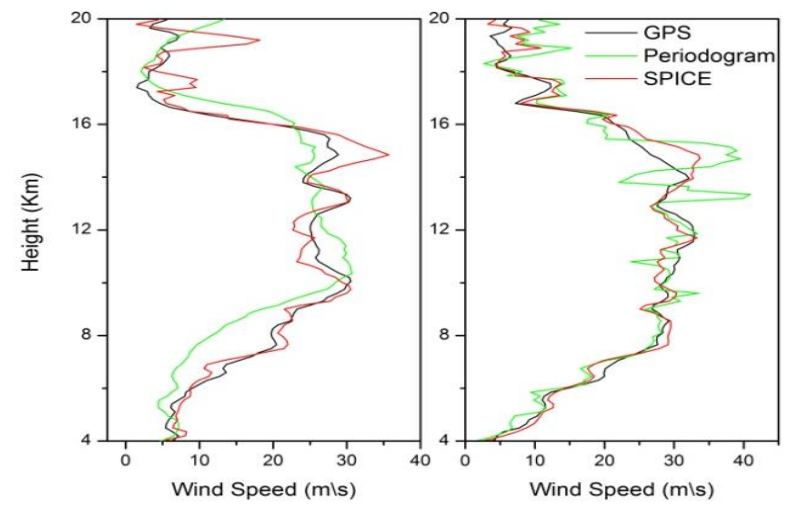

Fig. 5: Comparison of Wind Speed Using SPICE, Periodogram, and GPS Radiosonde for Radar Data Collected on February 9 and 10, 2015. 


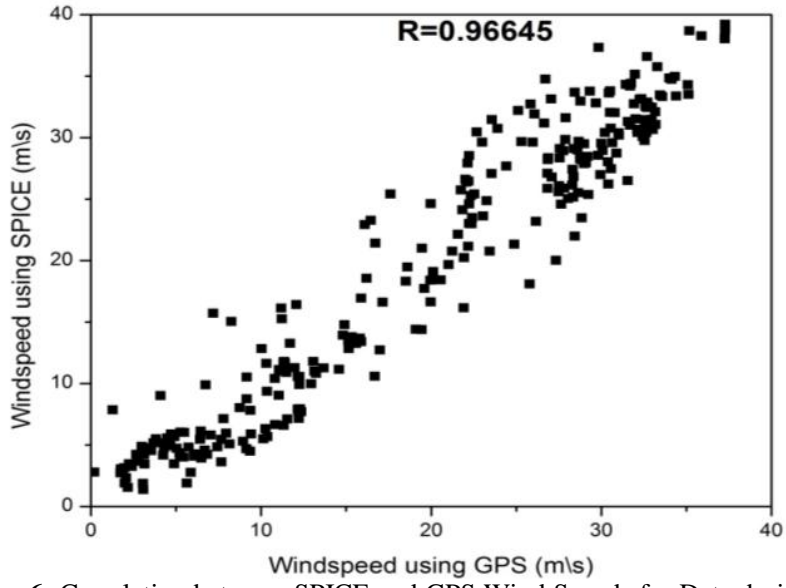

Fig. 6: Correlation between SPICE and GPS Wind Speeds for Data during $9^{\text {th }}-12^{\text {th }}$ February 2015.

\section{Conclusion}

A sparse iterative covariance based estimation approach is presented and applied to the radar data. The proposed sparse estimation method functions superior to the existing algorithm since the previously adopted methods of spectrum estimation have failed to perform well in this height range. The obtained wind velocities from the proposed algorithm are validated using the GPS sonde values. The correlation between wind speeds calculated using GPS and SPICE has been also presented for the radar data collected in February 2015 and a correlation factor of 0.96445 is obtained. The proposed method gives better results with high computational complexity. This is due to the fact that it is an iterative process involving matrix inversion. This can be carried through efficient methods resulting in less computational time.

\section{Acknowledgements}

The authors would like to thank National Atmospheric Research Laboratory (NARL), Gadanki for providing radar data and Centre of Excellence, Department of Electronics and Communication Engineering, Sri Venkateswara University College of Engineering for technical assistance.

\section{References}

[1] V.K. Anandan V.K. Anandan, Atmospheric Data ProcessorTechnical and User Reference Manual, NMRF, DOS Publication, Gadanki, India, 2002.

[2] V. Anandan, P. Balamuralidhar, P. Rao, and A. Jain, "A method for adaptive moments estimation technique applied to MST radar echoes," in Proc. Prog. Electromagn. Res. Symposium, 1996, pp. 360 365 .

[3] V. Anandan, C. Pan, T. Rajalakshmi, and G. R. Reddy, "Multitaper spectral analysis of atmospheric radar signals," Annual Geophysics, vol. 22, no. 11, pp. 3995-4003, 2004 https://doi.org/10.5194/angeo-22-3995-2004.

[4] V. Anandan, G. R. Reddy, and P. Rao, "Spectral analysis of atmospheric radar signal using higher order spectral estimation technique," IEEE Transactions on Geoscience and Remote sensing, vol. 39, no. 9, pp. 1890-1895, Sep. 2001. https://doi.org/10.1109/36.951079.

[5] D. U. M. Rao, T. S. Reddy, and G. R. Reddy, "Atmospheric radar signal processing using principal component analysis," Digit. Signal Process, vol. 32, pp. 79-84, Sep. 2014. https://doi.org/10.1016/j.dsp.2014.05.009.

[6] Neetha I. Eappen, T. Sreenivasulu Reddy, and G. Ramachandra Reddy, "Semiparametric algorithm for processing MST Radar data," IEEE Transactions on Geoscience and Remote Sensing, Vol: 54, No. 5, pp. 2713-2721, May 2016.

[7] P. Stoica, P. Babu, J. Li, "SPICE: a sparse covariance-based estimation method for array Processing", IEEE Transactions on Signal Processing, 59(2) 629-638. https://doi.org/10.1109/TSP.2010.2090525.
[8] P. Stoica, P. Babu, and J. Li, "New method of sparse parameter estimation in separable models and its use for spectral analysis of irregularly sampled data," IEEE Transactions on Signal Processing, vol. 59, no. 1, pp. 35-47, Jan. 2011. https://doi.org/10.1109/TSP.2010.2086452.

[9] P. Stoica, P. Babu, "SPICE and LIKES: two hyperparameter-free methods for sparse parameter estimation", Signal Processing, 92(7) (2012) 1580-1590. https://doi.org/10.1016/j.sigpro.2011.11.010.

[10] P. H. Hildebrand and R. Sekhon, "Objective determination of the noise level in Doppler spectra," Journal of Applied Meteorology, vol. 13, no. 7, pp. 808-811, Oct. 1974 https://doi.org/10.1175/15200450(1974)013<0808:ODOTNL>2.0.CO;2.

[11] PetreStoica, DaveZachariah, JianLi, "Weighted SPICE: A unifying approach for hyperparameter-free sparse estimation", Digital Signal Processing, pp.1-12, 2014.

[12] T. S. Reddy and G. R. Reddy, "Spectral analysis of atmospheric radar signal using filter banks polyphase approach," Digital Signal Processing, vol. 20, no. 4, pp. 1061- 1071, Jul. 2010. https://doi.org/10.1016/j.dsp.2009.10.032.

[13] S. Thatiparthi, R. Gudheti, and V. Sourirajan, "MST radar signal processing using wavelet-based denoising," IEEE Geoscience and Remote Sensing Letters, vol. 6, no. 4, pp. 752-756, Oct. 2009. https://doi.org/10.1109/LGRS.2009.2024556.

[14] T. Reddy and G. R. Reddy, "MST radar signal processing using Cepstral thresholding," IEEE Transactions on Geoscience and Remote Sensing, vol. 48, no. 6, pp. 2704-2710, Jun. 2010 https://doi.org/10.1109/TGRS.2009.2039937.

[15] P. Stoica and R. L. Moses, Spectral Analysis of Signals, Upper Saddle River, NJ: Prentice-Hall, 2005. 